\title{
B16 cell lysates plus polyinosinic-cytidylic acid effectively eradicate melanoma in a mouse model by acting as a prophylactic vaccine
}

 \\ ${ }^{1}$ Department of Dermatology, Chinese PLA General Hospital, Beijing 100853; \\ ${ }^{2}$ Medical College of PLA, Beijing 100853, P.R. China
}

Received July 23, 2013; Accepted March 17, 2014

DOI: $10.3892 / \mathrm{mmr} .2014 .2241$

\begin{abstract}
Th1 antigen-specific T cells secrete interferon- $\gamma$, which is able to kill antigen-specific cancer cells and is helpful for cancer vaccines. The aim of the present study was to explore whether B16 cell lysates plus polyinosinic-cytidylic acid (poly I:C) can effectively inhibit the progression of melanoma in an animal model. In the present study, C57BL/6 mice were divided into three groups, with each group containing more than six mice. The groups of mice were immunized twice with B16 cell lysates plus poly I:C, B16 cell lysates, or phosphate-buffered saline only, respectively. The in vivo results demonstrated that splenocytes from the mice immunized with B16 cell lysates plus poly $\mathrm{I}: \mathrm{C}$ contained higher percentages of $\mathrm{CD} 3^{+} \mathrm{CD} 8^{+} \mathrm{T}$ lymphocytes and $\mathrm{CD}^{+} \mathrm{CD}^{+} \mathrm{T}$ lymphocytes, which were detected by a fluorescence-activated cell sorter, and produced higher levels of antigen-specific splenocyte proliferation activity, as detected by MTT assay. The splenocytes from the mice immunized with B16 cell lysates in combination with poly I:C produced higher levels of interferon- $\gamma$, as detected by quantitative polymerase chain reaction and ELISA, as well as cytotoxic $\mathrm{T}$ lymphocyte activity when stimulated in vitro with B16 lysates. Additionally, subcutaneous immunization of the C57BL/6 mice with B16 cell lysates plus poly I:C conferred greater protection against tumor-forming B16 melanoma cells than that of the mice immunized with injection of B16 cell lysate alone. In conclusion, the cancer vaccine of B16 cell lysates plus poly I:C exerts potently protective effects that polarize responses toward Th1 and elicit antitumor immunity.
\end{abstract}

Correspondence to: Dr Hua Zhao, Department of Dermatology, Chinese PLA General Hospital, 28 Fu Xing Road, Beijing 100853, P.R. China

E-mail: zhaohuawork2008@163.com

*Contributed equally

Key words: melanoma, vaccine, antitumor

\section{Introduction}

Malignant melanoma is a serious disease arising from melanocytes which threatens human health in China and worldwide $(1,2)$. The incidence and mortality rate of malignant melanoma continues to increase at a higher rate than that of any other type of malignancy $(3,4)$. Although melanoma is curable if detected at an early localized stage, metastatic malignant melanoma has already become a therapeutic challenge (5). Hundreds of patients with advanced stage III or IV melanoma, particularly those with metastatic disease, have participated in studies of immunological therapy having failed on chemotherapy (6). Thus, ways to prevent and treat malignant melanoma using immunological methods are urgently required. Vaccination has been used for centuries, causing mortality due to infectious disease in humans to profoundly decrease, but a number of serious global diseases with no effective vaccines remain, including acquired immunodeficiency syndrome, influenza, malaria and cancer. It is harder to produce effective immune responses when using vaccines as a treatment for cancer, compared with when using preventive cancer vaccines $(7,8)$. The cancer vaccine for cervical tumors is the first vaccine to prevent human cancer. With the success of the cervical cancer vaccine, an increasing number of researchers have been working to identify novel and effective cancer vaccines. Thus, the aim of the present study is to identify novel vaccines that elicit stronger and more directed antitumor immune responses.

Cancer vaccine antigens include purified or recombinant proteins or peptides. They are frequently poorly immunogenic and require an effective adjuvant to help elicit protective immune responses based on antibodies or activated T cells (9-11). Polyinosinic-cytidylic acid (poly I:C) is a synthetic double-stranded RNA that has been used as an adjuvant (12). Poly I:C can act with distinct types of pathogen recognition receptors, which bind to toll-like receptor 3 (TLR3) or activate cytosolic RNA helicases, including retinoic acid-inducible gene 1 (RIG-I) and melanoma differentiation-associated gene 5 (MDA5) $(13,14)$. Therefore, activation of TLR3 and MDA5 could trigger effective inflammatory responses. Rapid innate immunity would be elicited and the magnitude and durability of type-1 T helper 
(Th1) cell immunity and $\mathrm{CD} 8^{+} \mathrm{T}$ cell immunity would be optimized compared with either pathway alone (15-18). Therefore, poly I:C was selected as the adjuvant for cancer vaccines in the present study.

The use of animal models is important in the study of malignant melanoma (19). The metastatic B16 mouse melanoma cell line originates from C57BL/6 mice and has a high metastatic frequency that easily mimics clinical metastatic melanoma (20). Thus, C57BL/6 mice bearing B16 melanoma were used as a mouse model for malignant melanoma in the present study. B16 melanoma lysates were used as the antigen combined with effective Th1 response-related poly I:C as an adjuvant in the cancer vaccine, which could effectively elicit the innate and adaptive immune responses. The objective of this study was to explore the role and identify the effectiveness of in vivo vaccination with $\mathrm{B} 16$ cell lysates on tumors in the mouse model. The study may aid the development of a vaccine for malignant melanoma and provide novel therapeutic ideas for this currently untreatable disease.

\section{Materials and methods}

Cell line. The B16 melanoma cell line was maintained in our laboratory at the Chinese PLA General Hospital (Beijing, China) and cultured in Dulbecco's modified Eagle's medium (DMEM; Invitrogen Life Technologies, Carlsbad, CA, USA) with $10 \%$ fetal bovine serum (FBS; Thermo Trace Ltd, Melbourne, Australia) at $37^{\circ} \mathrm{C}$ in an atmosphere of $95 \%$ air and $5 \% \mathrm{CO}_{2}$.

Mice. Male 6-8-week-old C57BL/6 mice were purchased from Vital River Biotechnology Co., Ltd. (Beijing, China). Animals were maintained in micro-isolator cages in specific pathogen-free conditions. They were handled under aseptic conditions following a protocol approved by the Institutional Animal Care and Use Committee of the Chinese PLA General Hospital (Beijing, China). All studies were approved by the Animal Study Committee of the Chinese PLA General Hospital.

Animal grouping and immunization. The mice were randomly divided into three groups. Each group contained more than six mice. Animals were injected intraperitoneally twice on days 1 and 15, with $50 \mu \mathrm{g} \mathrm{B} 16$ cell lysate antigen or $50 \mu \mathrm{g} \mathrm{B} 16$ cell lysate plus $50 \mu \mathrm{g}$ poly $\mathrm{I}: \mathrm{C}, 1.5 \% \mathrm{Al}(\mathrm{OH})_{3}$ or with $\mathrm{PBS}$. After the final immunization, the C57BL/6 mice were inoculated intraperitoneally with $1 \times 10^{5}$ melanoma cells suspended in $100 \mu 1$ PBS.

Tumor cell lysate. B16 cells were collected and washed three times with phosphate-buffered saline (PBS) buffer. Eight snap freeze-thaw cycles between liquid $\mathrm{N}_{2}$ and $37^{\circ} \mathrm{C}$ were conducted. The cells were centrifuged at $500 \mathrm{x}$ g to obtain the lysate, which was then filtered with a $70-\mathrm{mm}$ Falcon filter (BD Biosciences, Erembodegen, Belgium). Coomassie blue staining method was used to measure the amount of protein and was performed according to the manufacturer's instructions (Benda Biotechnology, Co., Shanghai, China). The lysate was separated and kept frozen in liquid $\mathrm{N}_{2}$ until required.
Splenocyte proliferation assay. Cell proliferation levels were determined using the MTT assay (21). One week after the final immunization, single-cell suspensions from the mice in each group were prepared under sterile conditions. Red blood cells (RBCs) were lysed using lysis buffer containing $0.75 \% \mathrm{NH}_{4} \mathrm{Cl}$ in Tris-buffer. Cell concentrations were adjusted to $3 \times 10^{6}$ cells $/ \mathrm{ml}$ in DMEM supplemented with $10 \%$ FBS. Samples $(100 \mu l)$ of the suspensions were dispensed into 96-well round-bottom culture plates (Costar, Tewksbury, MA, USA) and incubated with $10 \mu \mathrm{g} / \mathrm{ml} \mathrm{B} 16$ melanoma cell lysate for $48 \mathrm{~h}$ at $37^{\circ} \mathrm{C}$ in a $5 \% \mathrm{CO}_{2}$ humid incubator.

Quantitative PCR analysis of $m R N A$ expression. Splenocytes from the immunized mice were cultured in six-well plates for $24 \mathrm{~h}$ at $37^{\circ} \mathrm{C}$ in the presence of $5 \% \mathrm{CO}_{2}$, with or without $10 \mu \mathrm{g} / \mathrm{ml}$ B16 cell lysate. Total RNA was extracted with an RNApure kit (Bioteke, Beijing, China) and retrotranscribed with murine leukemia virus (MLV) reverse transcriptase (RT) (Invitrogen Life Technologies). PCR amplifications were performed using a 7500 Real-Time PCR system (Applied Biosystems, Foster City, CA, USA) and each sample was tested in triplicate. Thermal cycling conditions were 40 cycles of $12 \mathrm{sec}$ at $95^{\circ} \mathrm{C}$ and $1 \mathrm{~min}$ at $60^{\circ} \mathrm{C}$ using SYBR-Green (Invitrogen Life Technologies). $\beta$-actin was used as the internal reference gene. The primers used were as follows: Interferon- $\gamma$ $($ IFN- $\gamma)$, 5'-CAGCAACAGCAAGGCGAAA-3' and 5'-CTGGACCTGTGGGTTGTTGAC-3'; $\beta$-actin, 5'-AGAGGGAAATCGTGCGTGAC-3' and 5'-CAATAGTGA TGACCTGGCCGT-3'.

Fluorescence-activated cell sorter (FACS) analysis. Seven days after the final immunization, single cell suspensions were performed for spleen T-cell subtype analysis. RBCs from $50 \mu 1$ heparin-treated orbital blood were lysed with RBC lysis buffer (eBioscience, San Diego, CA, USA). Lymphocytes were stained with $100 \mu \mathrm{l}$ PBS plus $1 \%$ bovine serum albumin and $0.1 \% \mathrm{NaN}_{3}$ together with $5 \mu \mathrm{l}$ fluorescein isothiocyanate-conjugated anti-CD3 monoclonal antibody (mAb) followed by simultaneous staining with $5 \mu$ phycoerythrin anti-CD4 or anti-CD8 $\mathrm{mAb}$, and then incubated for $20 \mathrm{~min}$ at $4^{\circ} \mathrm{C}$. Flow cytometry was performed using CellQuest software and a FACScan flow cytometer (Becton Dickinson, San Jose, CA, USA), with FlowJo software (Tree Star Inc., Ashland, OR, USA) used for data analysis.

Statistical analysis. Survival curves of the animals treated with different protocols were plotted according to the Kaplan-Meier method. Statistical significance in different treatment groups was compared using the log-rank test. $\mathrm{P}<0.05$ was considered to indicate a statistically significant difference.

\section{Results}

Antigen-specific splenocytes proliferate in mice immunized with B16 cell lysates plus poly I:C. In order to detect whether the splenocytes of the mice immunized with B16 cell lysates plus poly I:C had an elevated antigen-specific proliferation rate, the cell numbers were measured by MTT assay. Ten 


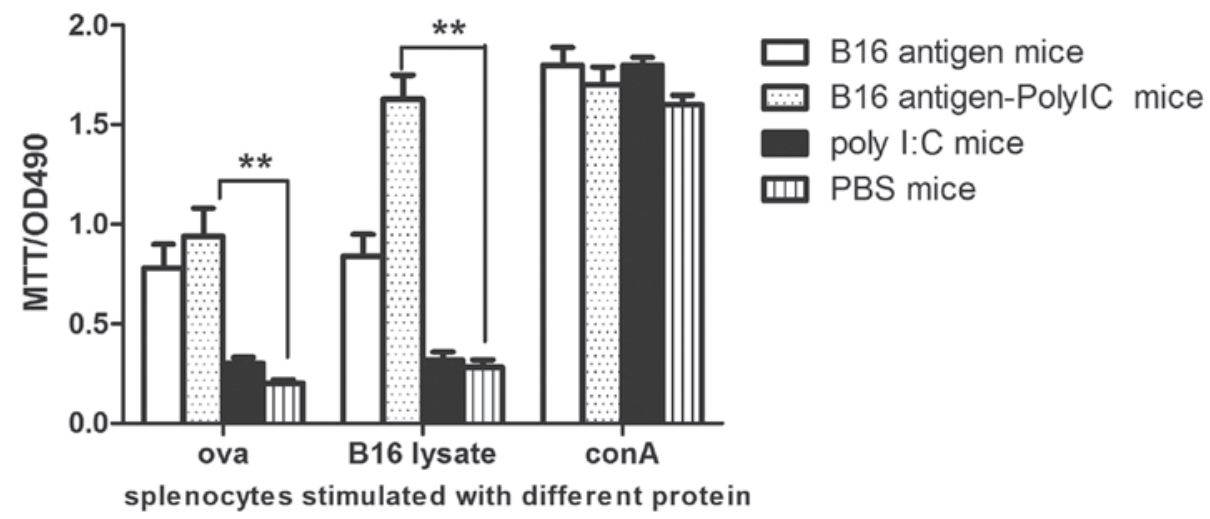

Figure 1. Splenocyte proliferation measured by MTT assay. Splenocyte numbers were measured in response to treatment with $10 \mu \mathrm{g} / \mathrm{ml} \mathrm{ovalbumin,} 50 \mu \mathrm{g} / \mathrm{ml}$ B16 lysate or $10 \mu \mathrm{g} / \mathrm{ml}$ final concentration of ConA for $24 \mathrm{~h}$. Data are shown as the mean \pm standard error of the mean of at least three independent experiments on different individuals. ${ }^{* *} \mathrm{P}<0.01$ compared with B16 antigen group. Poly I:C, polyinosinic-cytidylic acid; PBS, phosphate-buffered saline; OD, optical density.

A
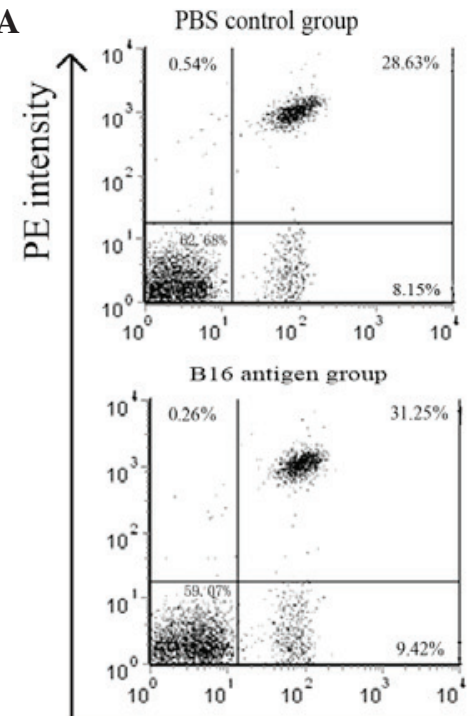

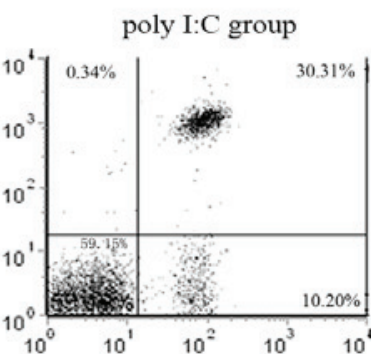

B16 antigen-poly I:C group



B

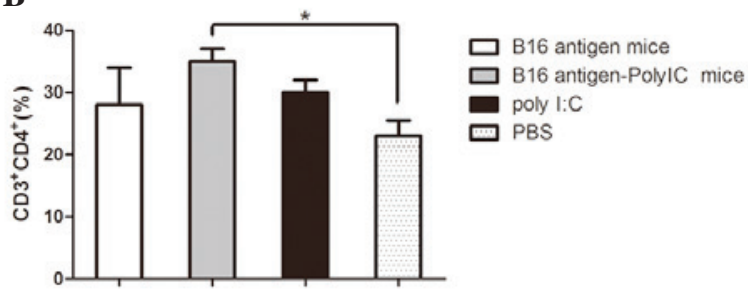

Figure 2. $\mathrm{CD}^{+} \mathrm{CD}^{+} \mathrm{T}$ cell subpopulations. Mice were immunized as described in Materials and methods. Seven days after the final immunization, leukocytes were collected from peripheral blood samples in the venous plexus of the eyes. Red blood cells were lysed with red blood cell lysis buffer, and the lymphocytes were stained for the T cell surface markers CD3 (fluorescein isothiocyanate-conjugated monoclonal antibody) and CD4 (phycoerythrin-conjugated monoclonal antibody). (A) $\mathrm{CD}^{+} \mathrm{CD}^{+} \mathrm{T}$ cell subpopulations was detected by FACS. (B) Histogram of $\mathrm{CD} 4^{+} \mathrm{CD} 3^{+} \mathrm{T}$ cell subpopulations. $\mathrm{P}<0.05$ compared with $\mathrm{PBS}$ group. $\mathrm{n}=6$; values are the mean \pm standard error of the mean. Poly I:C, polyinosinic-cytidylic acid; PBS, phosphate-buffered saline; FACS, fluorescence-activated cell sorting.

days after the final immunization, spleens from mice in each group were removed and the rate of splenocyte proliferation was measured. After in vitro stimulation with B16 lysates for $24 \mathrm{~h}$, the splenocytes from the mice immunized with B16 lysates in combination with poly I:C were significantly more numerous than those in either control group $(\mathrm{P}<0.01$; Fig. 1). The cells treated with Concanavalin A (ConA) were used as positive controls and untreated cells were used as negative controls.

Number of $\mathrm{CD}^{+} \mathrm{CD}^{+} \mathrm{T}$ lymphocytes and $\mathrm{CD} 8^{+} \mathrm{CD} 3^{+}$ $T$ lymphocytes increases in mice immunized with B16 cell lysate plus poly I:C. T-cell subsets were also analyzed. The percentages of $\mathrm{T}$ helper cells $\left(\mathrm{CD} 4^{+} \mathrm{CD} 3^{+} \mathrm{T}\right.$ lymphocytes) and cytotoxic $\mathrm{T}$ cells $\left(\mathrm{CD} 8^{+} \mathrm{CD} 3^{+} \mathrm{T}\right.$ lymphocytes) were determined by flow cytometry. As shown in Fig. 2, the mice immu- nized with B16 cell lysate plus poly I:C contained a higher percentage of $\mathrm{CD}^{+} \mathrm{CD}^{+} \mathrm{T}$ lymphocytes in their peripheral blood than that of the mice injected with PBS. In addition, the frequency of $\mathrm{CD}^{+} \mathrm{CD}^{+} \mathrm{T}$ lymphocytes in the peripheral blood appeared to increase in the mice immunized by B16 cell lysates plus poly I:C compared with that of the mice injected with PBS (Fig. 3).

IFN- $\gamma$ expression determined by $q P C R$ and cytokine secretion measured by ELISA. C57BL/6 mice were immunized twice with B16 cell lysates in combination with poly I:C, the antigen alone, or PBS. Ten days after the final immunization, spleens were removed and splenocytes of single cell suspension were prepared. In order to compare the cell-mediated immune responses among the three groups, splenocytes from the immunized mice were in vitro-stimulated with B16 
A



B

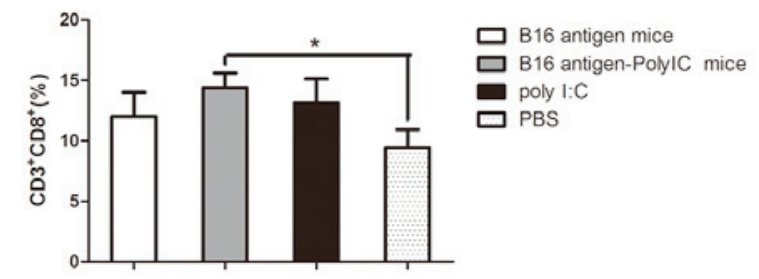

Figure 3. $\mathrm{CD}^{+} \mathrm{CD}^{+} \mathrm{T}$ cell subpopulations. Seven days after the final immunization, peripheral blood samples were collected from the venous plexus of the eyes. (A) Red blood cells were lysed with red blood cell lysis buffer and the lymphocytes were stained for the T cell surface markers CD3 (fluorescein isothiocyanate-conjugated monoclonal antibody) and CD8 (phycoerythrinconjugated monoclonal antibody) using a FACS assay. (B) Histogram of $\mathrm{CD} 4^{+} \mathrm{CD}^{+} \mathrm{T}$ cell subpopulations. ${ }^{*} \mathrm{P}<0.05$ compared with $\mathrm{PBS}$ group. $\mathrm{n}=6$; values are the mean \pm standard error of the mean. Poly $\mathrm{I}: \mathrm{C}$, polyinosiniccytidylic acid; PBS, phosphate-buffered saline; FACS, fluorescence-activated cell sorting.

antigen for $24 \mathrm{~h}$ and IFN- $\gamma$ mRNA levels were analyzed using qRT-PCR (amplification curve shown in Fig. 4A). The mean relative IFN- $\gamma$ mRNA expression in the mice immunized with B16 cell lysate plus poly I:C was significantly higher than that in the mice immunized with the B16 cell lysate only (P<0.01; Fig. 4B). IFN- $\gamma$ protein levels were also examined by ELISA. As expected, the mean IFN- $\gamma$ production in the mice immunized with B16 cell lysate was higher than that in the antigen-immunized group following in vitro stimulation with B16 cell lysates (Fig. 4C).

Cytotoxic T lymphocyte (CTL) activity. To demonstrate the cytotoxic activity of splenocytes from the immunized mice for B16 cells, the release of cytosolic lactate dehydrogenase (LDH) into the culture medium by a damaged B16 melanoma cell line was tested. Ten days after the final immunization, damage to the membranes of B16 melanoma cells was evaluated in a $24 \mathrm{~h}$ cytotoxicity assay by measuring LDH release. LDH release assays were performed with splenocytes as effector cells and B16 melanoma cells as target cells. The effector-to-target cell ratios were 5:1, 10:1 and 20:1. As shown in Fig. 5, the CTL response was significantly higher

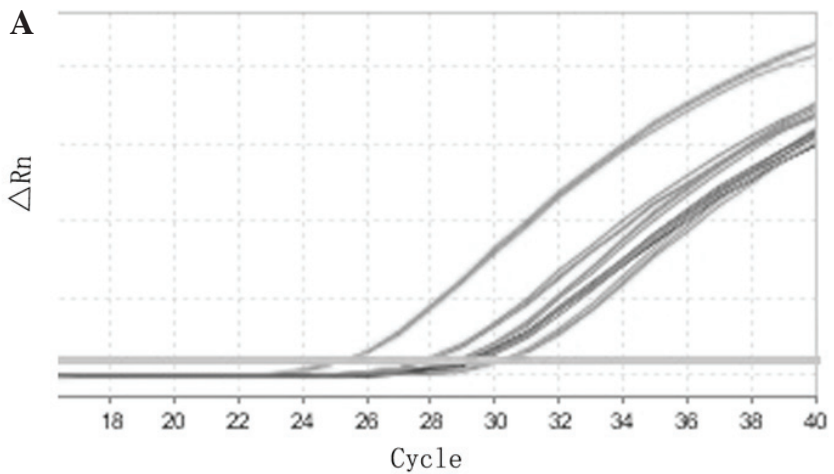

B

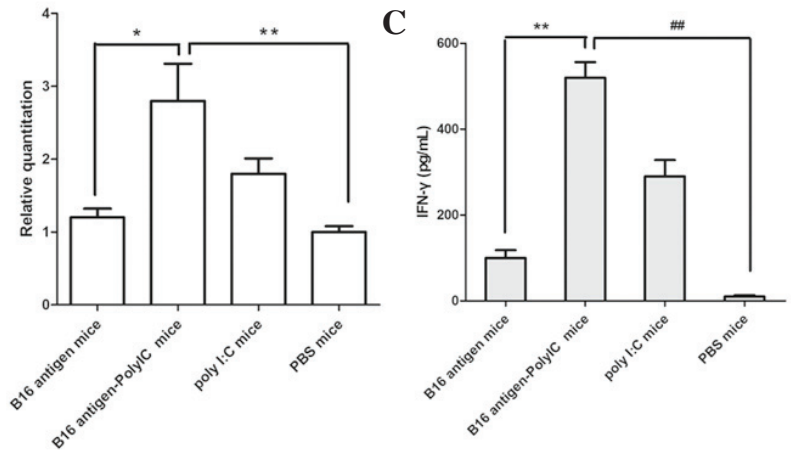

Figure 4. IFN- $\gamma$ gene expression and protein secretion in splenocytes harvested from immunized mice following in vitro restimulation. Splenocytes from the mice immunized with B16 antigen combined with or without poly I:C were isolated seven days after the final immunization and incubated in vitro with B16 lysate for $24 \mathrm{~h}$. (A) Amplification curve of IFN- $\gamma$ in mice immunized by B16 antigen or B16 antigen with poly I:C. (B) IFN- $\gamma$ gene expression. (C) IFN- $\gamma$ production detected by ELISA. Data are the mean \pm standard deviation of the relative quantities of cytokine mRNAs. ${ }^{*} \mathrm{P}<0.05,{ }^{* *} \mathrm{P}<0.01$ and ${ }^{\# \#} \mathrm{P}<0.01$. Poly I:C, polyinosinic-cytidylic acid; PBS, phosphate-buffered saline; IFN- $\gamma$, interferon- $\gamma$.

in the mice immunized with B16 lysate plus poly $\mathrm{I}: \mathrm{C}$ than that in those immunized with $\mathrm{B} 16$ lysate alone $(\mathrm{P}<0.01)$ or PBS $(\mathrm{P}<0.01)$. B16 melanoma cells and splenocytes from the immunized mice did not release any LDH when measured at $24 \mathrm{~h}$. These were cultured alone in DMEM medium and were used as negative controls.

Improved antitumor effects in B16 lysate plus poly I:C vaccinated mice compared with those in mice immunized with B16 lysate or PBS only. To assess in vivo antitumor responses in the immunized mice, the survival rates were evaluated in the immunized groups. Following the final immunization, all the mice received an intraperitoneal challenge of $1 \times 10^{5}$ B16 melanoma cells. The results revealed that subcutaneous immunization of C57BL/6 mice with B16 cell lysate plus poly I:C conferred improved protection against B16 melanoma cells than did immunization with B16 cell lysate or PBS alone. The survival rate of the B16 plus poly I:C group was significantly higher than that of the B16 lysate group and $\mathrm{PBS}$ group $(\mathrm{P}=0.029$ vs. $\mathrm{B} 16$ lysate group, $\mathrm{P}=0.003$ vs. PBS group), as shown in Fig. 6. Also the antitumor effects in the mice immunized by B16 antigen plus poly I:C were significantly greater than those in mice immunized by B16 antigen plus $\mathrm{Al}_{2}(\mathrm{OH})_{3}$, which is used as the positive adjuvant in market. 




Figure 5. CTL assays. LDH release assays were performed with splenocytes as effector cells and B16 melanoma cells as target cells. The ratios of effector cell to target cell (E:T) were 5:1, 10:1 and 20:1. Specific lysis of target cells was calculated using the following formula: Specific lysis $(\%)=[($ experimental LDH release) - (spontaneous LDH release)]/[(maximum LDH release) - (spontaneous LDH release)] x 100. All of the experiments were performed in triplicate and repeated 4 times and the results were calculated as the mean \pm standard deviation. $(\mathrm{P}<0.01)$. Poly $\mathrm{I}: \mathrm{C}$, polyinosinic-cytidylic acid; PBS, phosphate-buffered saline; LDH, lactate dehydrogenase; CTL, cytotoxic T lymphocyte.

\section{Survival proportions}

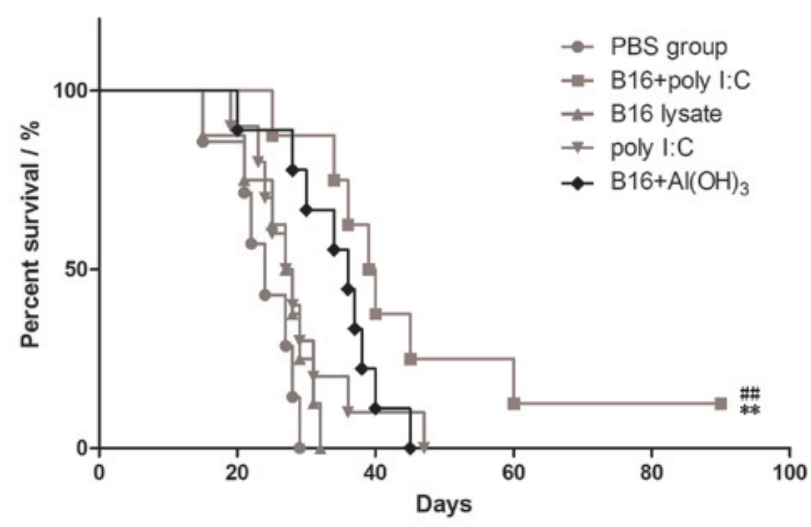

Figure 6. Survival proportions of immunized mice following lethal melanoma B16 challenge. C57BL/6 mice were immunized subcutaneously on the thigh with $\mathrm{B} 16$ in combination with poly $\mathrm{I}: \mathrm{C}, \mathrm{Al}(\mathrm{OH})_{3}$ and $\mathrm{B} 16$ lysate, or PBS alone. One week after the final immunization, mice were challenged subcutaneously with $2 \times 10^{5}$ B16 melanoma cells. Each group contained more than six mice. The survival rate was determined as $100 \mathrm{x}$ (number of survivors)/(number of challenged mice). Poly I:C, polyinosinic-cytidylic acid; PBS, phosphate-buffered saline. ${ }^{* *} \mathrm{P}=0.029$ vs. B16 lysate group; ${ }^{\#} \mathrm{P}=0.003$ vs. PBS group.

\section{Discussion}

Cancer vaccines have been studied for several decades and are intended either to prevent the development of cancer or to treat existing cancers (22-24). However, advances in this field have been slower than those in other forms of immunotherapy (24-26). In order to overcome the poor immunogenicity of tumors, administration of tumor antigens with an effective adjuvant is theoretically a good strategy. The adjuvant could be a molecule that is able to activate dendritic cells (DCs) and induce potent antitumor T-cell immune responses (27). Ligands of toll-like receptors (TLRs) are the best candidates to activate DCs and can lead to DC maturation. Thus, with the aim of inducing potent antitumor T-cell responses, poly $\mathrm{I}: \mathrm{C}$, the ligand of TLR3, was selected as the adjuvant of the tumor antigen to strongly activate DCs and facilitate T-cell priming in the present study $(14,26,28,29)$. The results of the study clearly demonstrate that poly I:C was an effective adjuvant for B16 cell lysates and successfully induced effective antitumor immune responses.

It is reported that antitumor activity requires the participation of $\mathrm{CD}^{+} \mathrm{CD}^{+}$and $\mathrm{CD}^{+} \mathrm{CD}^{+} \mathrm{T}$ lymphocytes $(30,31)$. Th1 cells exhibit a critical role in cellular immunity by releasing cytokines that activate $\mathrm{CD} 8^{+} \mathrm{T}$ cells. Thus, activation of CD4 $\mathrm{T}$ helper cells is an important step for the priming of memory CTL responses. $\mathrm{CD}^{+} \mathrm{T}$ cells are the main effector cells with CTL activity, however the main cells producing cytokines are $\mathrm{CD}^{+}{ }^{+}$Th1 cells, including interleukin-2, IFN- $\gamma$ and tumor necrosis factor- $\alpha$. In the present study, the antigen-specific Th1 responses and CTL response after the final immunization in different groups of mice were measured. Supporting the idea that the induction of IFN- $\gamma$ suggests polarization towards the Th1 response, the group of mice immunized with B16 cell lysate in combination with poly I:C produced increased levels of IFN- $\gamma$ and specific CTL activity when stimulated in vitro with B16 melanoma cell lysates. Increased levels of IFN- $\gamma$ and CTL activity contributed to the observed antitumor effect in the mice immunized with B16 cell lysate plus poly I:C. In addition, this was consistent with the potent antigen-specific antitumor immunity previously observed in the murine B16 melanoma challenge model (32-34). The survival rate of the mice immunized with B16 cell lysate in combination with poly I:C was significantly higher than that of the group immunized with B16 antigen or PBS only. It was found in previous studies that immunization with B16 plus poly I:C was able to fully protect mice in prophylactic vaccination experiments, not only in the short-term but also in the long-term (35-37).

Although the B16 melanoma cell lysate was used as a cancer antigen to assess the antitumor effects of the cancer vaccine in the current study, it is reasonable to hypothesize that poly I:C could confer adjuvant properties when used in combination with a variety of viral antigenic peptides or tumor-specific antigens. In addition, the findings of this study imply that the adjuvant poly I:C may be useful for eliciting immune responses or breaking immune tolerance in cases of spontaneous tumors as well as in cases of infections caused by the hepatitis B virus, the human papillomavirus, and the human immunodeficiency virus.

In conclusion, in vivo experiments with the mouse model in the present study demonstrated that the mice that received B16 cell lysate plus poly I:C exhibited enhanced antitumor prophylactic and therapeutic efficacy, which was associated with increased IFN- $\gamma$ production and induction of cytotoxic $\mathrm{T}$ lymphocyte activity. It is hypothesized that this strategy could be useful for the treatment of malignant tumors and metastasis. 


\section{References}

1. Lee C, Collichio F, Ollila D and Moschos S: Historical review of melanoma treatment and outcomes. Clin Dermatol 31: 141-147, 2013.

2. Chen LL, Jaimes N, Barker CA, Busam KJ and Marghoob AA: Desmoplastic melanoma: a review. J Am Acad Dermatol 68: 825-833, 2013

3. Vourc'h-Jourdain M, Martin L, Barbarot S; aRED: Large congenital melanocytic nevi: therapeutic management and melanoma risk: a systematic review. J Am Acad Dermatol 68: 493-498, 2013

4. Ma C and Armstrong AW: Severe adverse events from the treatment of advanced melanoma: a systematic review of severe side effects associated with ipilimumab, vemurafenib, interferon alfa-2b, dacarbazine and interleukin-2. J Dermatolog Treat 25: 401-408, 2014.

5. Singh S, Nagpal SJ, Murad MH, et al: Inflammatory bowel disease is associated with an increased risk of melanoma: a systematic review and meta-analysis. Clin Gastroenterol Hepatol 12 : 210-218, 2014.

6. Gogas H, Polyzos A and Kirkwood J: Immunotherapy for advanced melanoma: fulfilling the promise. Cancer Treat Rev 39: 879-885, 2013.

7. Engell-Noerregaard L, Hansen TH, Andersen MH, Thor Straten $P$ and Svane IM: Review of clinical studies on dendritic cell-based vaccination of patients with malignant melanoma: assessment of correlation between clinical response and vaccine parameters. Cancer Immunol Immunother 58: 1-14, 2009.

8. Zhang S, Wang Q and Miao B: Review: dendritic cell-based vaccine in the treatment of patients with advanced melanoma. Cancer Biother Radiopharm 22: 501-507, 2007.

9. Harris RC, Chianese-Bullock KA, Petroni GR, et al: The vaccine-site microenvironment induced by injection of incomplete Freund's adjuvant, with or without melanoma peptides. J Immunother 35: 78-88, 2012.

10. Cho DY, Yang WK, Lee HC, et al: Adjuvant immunotherapy with whole-cell lysate dendritic cells vaccine for glioblastoma multiforme: a phase II clinical trial. World Neurosurg 77: 736-744, 2012

11. Wang ZY, Xing Y, Liu B, et al: Protective antitumor immunity induced by tumor cell lysates conjugated with diphtheria toxin and adjuvant epitope in mouse breast tumor models. Chin J Cancer 31: 295-305, 2012.

12. Cui Z and Qiu F: Synthetic double-stranded RNA poly(I:C) as a potent peptide vaccine adjuvant: therapeutic activity against human cervical cancer in a rodent model Cancer Immunol Immunother 55: 1267-1279, 2006.

13. Kato A, Truong-Tran AQ, Scott AL, Matsumoto $K$ and Schleimer RP: Airway epithelial cells produce B cell-activating factor of TNF family by an IFN-beta-dependent mechanism. J Immunol 177: 7164-7172, 2006.

14. Inao T, Harashima N, Monma H, et al: Antitumor effects of cytoplasmic delivery of an innate adjuvant receptor ligand, poly(I:C), on human breast cancer. Breast Cancer Res Treat 134: 89-100, 2012.

15. Rajan JV, Warren SE, Miao EA and Aderem A: Activation of the NLRP3 inflammasome by intracellular poly I:C. FEBS Lett 584: 4627-4632, 2010.

16. Trumpfheller C, Caskey M, Nchinda G, et al: The microbial mimic poly IC induces durable and protective $\mathrm{CD} 4^{+} \mathrm{T}$ cell immunity together with a dendritic cell targeted vaccine. Proc Natl Acad Sci USA 105: 2574-2579, 2008.

17. Wörnle M, Sauter M, Kastenmüller K, et al: Novel role of toll-like receptor 3, RIG-I and MDA5 in poly (I:C) RNA-induced mesothelial inflammation. Mol Cell Biochem 322: 193-206, 2009.

18. Longhi MP, Trumpfheller C, Idoyaga J, et al: Dendritic cells require a systemic type I interferon response to mature and induce CD $4^{+}$Th1 immunity with poly IC as adjuvant. J Exp Med 206: 1589-1602, 2009.
19. Bose A, Lowe DB, Rao A and Storkus WJ: Combined vaccine+axitinib therapy yields superior antitumor efficacy in a murine melanoma model. Melanoma Res 22: 236-243, 2012.

20. Kayaga J, Souberbielle BE, Sheikh N, et al: Anti-tumour activity against B16-F10 melanoma with a GM-CSF secreting allogeneic tumour cell vaccine. Gene Ther 6: 1475-1481, 1999.

21. Mosmann T: Rapid colorimetric assay for cellular growth and survival: application to proliferation and cytotoxicity assays. J Immunol Methods 65: 55-63, 1983.

22. Kirkwood JM, Moschos S and Wang W: Strategies for the development of more effective adjuvant therapy of melanoma: current and future explorations of antibodies, cytokines, vaccines, and combinations. Clin Cancer Res 12: 2331s-2336s, 2006.

23. Kirkwood JM, Strawderman MH, Ernstoff MS, Smith TJ, Borden EC and Blum RH: Interferon alfa-2b adjuvant therapy of high-risk resected cutaneous melanoma: the Eastern Cooperative Oncology Group Trial EST 1684. J Clin Oncol 14: 7-17, 1996

24. Terando A, Sabel MS and Sondak VK: Melanoma: adjuvant therapy and other treatment options. Curr Treat Options Oncol 4: 187-199, 2003.

25. Krishnan L, Deschatelets L, Stark FC, Gurnani K and Sprott GD: Archaeosome adjuvant overcomes tolerance to tumor-associated melanoma antigens inducing protective CD8 T cell responses. Clin Dev Immunol 2010: 578432, 2010.

26. Mechl Z and Kopecný J: Current results with surgery and adjuvant chemotherapy in malignant melanoma. Arch Geschwulstforsch 56: 367-371, 1986 (In German).

27. Olivier A, Sainz-Perez A, Dong H, Sparwasser T, Majlessi L and Leclerc C: The adjuvant effect of TLR agonists on CD4(+) effector T cells is under the indirect control of regulatory $\mathrm{T}$ cells. Eur J Immunol 41: 2303-2313, 2011.

28. Huang YK, Zheng Z, Cheng CX, Wang LY, Li YR and Qiu F: The antitumor effect of the toll-like receptor 3 ligand polyinosinic-cytidylic acid as an adjuvant. Cancer Immunol Immunother 62: 237-244, 2013.

29. Martínez-Gil L, Goff PH, Hai R, García-Sastre A, Shaw ML and Palese P: A Sendai virus-derived RNA agonist of RIG-I as a virus vaccine adjuvant. J Virol 87: 1290-1300, 2013.

30. Wang S, Du W, Zhang H, et al: Biological characteristics and antitumor activity of CIK cells activated by recombinant human fibronectin for human lung cancer cell lines in vitro. Zhongguo Fei Ai Za Zhi 13: 277-281, 2010.

31. Starska K, Głowacka E, Kulig A, Lewy-Trenda I, Bryś M and Lewkowicz P: The role of tumor cells in the modification of T lymphocytes activity - the expression of the early $\mathrm{CD} 69^{+}, \mathrm{CD} 71^{+}$ and the late $\mathrm{CD} 25^{+}, \mathrm{CD} 26^{+}, \mathrm{HLA} / \mathrm{DR}^{+}$activation markers on $\mathrm{T}$ $\mathrm{CD}^{+}$and $\mathrm{CD}^{+}$cells in squamous cell laryngeal carcinoma. Part I. Folia Histochem Cytobiol 49: 579-592, 2011.

32. Török L: Adjuvant interferon treatment of melanoma. Magy Onkol 47: 105-107, 2003 (In Hungarian).

33. Mitchell MS, Kan-Mitchell J, Kempf RA, Harel W, Shau HY and Lind S: Active specific immunotherapy for melanoma: phase I trial of allogeneic lysates and a novel adjuvant. Cancer Res 48: 5883-5893, 1988

34. Jasani B, Navabi $\mathrm{H}$ and Adams M: Ampligen: a potential toll-like 3 receptor adjuvant for immunotherapy of cancer. Vaccine 27: 3401-3404, 2009.

35. May M, Kendel F, Hoschke B, et al: Adjuvant autologous tumour cell vaccination in patients with renal cell carcinoma. Overall survival analysis with a follow-up period in excess of more than 10 years. Urologe A 48: 1075-1083, 2009 (In German).

36. May M, Brookman-May S, Hoschke B, et al: Ten-year survival analysis for renal carcinoma patients treated with an autologous tumour lysate vaccine in an adjuvant setting. Cancer Immunol Immunother 59: 687-695, 2010.

37. Markowicz S, Nowecki ZI, Rutkowski P, et al: Adjuvant vaccination with melanoma antigen-pulsed dendritic cells in stage III melanoma patients. Med Oncol 29: 2966-2977, 2012. 